\title{
The impact of factor infusion frequency on health-related quality of life in people with haemophilia
}

Gabriel Pedra, Pia Christoffersen, Kate Khair, Xin Ying Lee, Sonia O'Hara, Jamie O'Hara, John Pasi

Background: Some studies suggest that people with haemophilia $(\mathrm{PwH})$ who use prophylaxis value low frequency of clotting factor administration more than a lower risk of bleeding. However, more frequent infusions offer the potential of reducing joint disease and pain, which in turn may improve functioning and quality of life. Aims: To explore the impact on healthrelated quality of life (HRQOL) aspects of haemophilia associated with adherence and annual infusion rate in the context of factors influencing treatment that are important to patients, including prophylaxis, chronic pain, concomitant conditions and hospital admission. Materials and methods: HRQoL was

GABRIEL PEDRA

HCD Economics, Daresbury, UK. Email: gabriel.pedra@

hcdeconomics.com

PIA CHRISTOFFERSEN

Novo Nordisk A/S, Søborg, Denmark

KATE KHAIR

Centre for Outcomes and Experience Research in

Children's Health Illness and Disability (ORCHID), Great

Ormond Street Hospital, London; Haemnet, UK

XIN YING LEE

Novo Nordisk A/S, Søborg, Denmark

SONIA O'HARA

HCD Economics, Daresbury, UK

JAMIE O'HARA

Faculty of Health and Social Care, University of Chester, UK

JOHN PASI

Haemophilia Centre, Royal London Hospital, UK

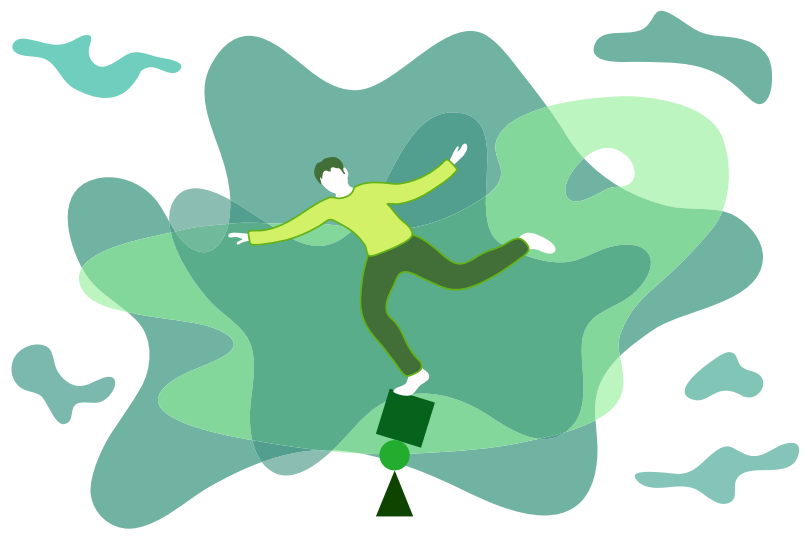

The impact of infusion frequency on health-related quality of life in people with haemophilia is variable, with influencing factors including haemophilia severity and experience of pain. A recent study indicates a need to balance burden of treatment with protection against bleeds.

assessed in participants with severe haemophilia in the 'Cost of Haemophilia in Europe: a Socioeconomic Survey' (CHESS) study who were using prophylaxis. Patients using on-demand treatment were excluded. This multivariate analysis examined the interaction between factors potentially influencing treatment and HRQoL, and minor and major bleeds. Results: From the total CHESS population ( $n=1,285), 338$ (26\%) participants provided responses for major and minor bleeds and target joints, and $145(11 \%)$ provided EQ-5D-3L responses. Major and minor bleeds were associated with pain. Patients with severe chronic pain reported a substantial negative impact on $\mathrm{HRQOL}$; but this was significantly improved by increases in the annual infusion rate. This was not apparent in 
participants with mild or moderate pain. Conclusion: Increasing the frequency of prophylaxis infusions is associated with improved quality of life in $\mathrm{PwH}$ who have severe chronic pain. However, increasing the number of infusions per week in those with mild or moderate chronic pain with the intention of improving prophylactic effect may not have the same effect.

Keywords: Haemophilia, quality of life, infusion frequency, chronic pain, CHESS study

ecommendations from the World Federation for Hemophilia for the management of haemophilia state that prophylaxis with factor replacement therapy should maintain trough factor levels of $>1 \%$, with the aim of minimising bleeds and reducing the long-term risk of joint damage due to haemarthrosis ${ }^{[1]}$. However, the advent of extended half-life factors and non-factor products such as emicizumab has raised expectations among clinicians of improved quality of life through a reduction in infusion frequency, greater convenience and better tailored treatment ${ }^{[2]}$.

The infusion frequency required to achieve trough factor VIII (FVIII) levels of $>1 \%$ ranges from once a week to alternate days among most people with haemophilia A. However, even these dose regimens do not prevent all spontaneous bleeds despite high adherence ${ }^{[3]}$, and the residual joint arthropathy continues to develop, so that young men in their 20s and 30s report increased pain and limitation of function ${ }^{[4,5]}$. Some European countries are now seeing as many as $14-16 \%$ of patients using daily intravenous infusions ${ }^{[6]}$.

Extended half-life (EHL) products have already changed clinical practice in economically developed countries, but standard half-life products still dominate prescribing elsewhere. EHL FVIII can maintain target trough levels with a reduced infusion frequency whereas EHL factor IX (FIX) offers higher trough levels and a lower frequency of infusions ${ }^{[7]}$. It is clear that maintenance of higher trough levels reduces the risk of bleeds ${ }^{[8]}$. The choice between fewer infusions or higher trough levels is likely to be influenced by patient preference, available resources and cost, and may not be exclusively one pathway or the other but a compromise representing a balance somewhere in between. When considering the best outcome from the patient's perspective, it is important to understand the likely impact on clinical endpoints and quality of life. Patient preference studies suggest that patients value low frequency of administration more than a lower risk of bleeding ${ }^{[9,10]}$ and this was the commonest reason cited for considering a switch from a traditional standard half-life (SHL) product to an EHL factor ${ }^{[11]}$. However, joint disease and pain also impair healthrelated quality of life (HRQoL) and daily functioning ${ }^{[12,13]}$, and these studies may not fully represent the potential benefits available to patients from maintaining higher trough factor levels.

The aim of this study was to test the hypothesis that HRQoL in people with haemophilia $(\mathrm{PwH})$ is influenced by factors that are important to them, including prophylaxis, chronic pain, concomitant conditions and hospital admission.

\section{MATERIALS AND METHODS}

\section{The CHESS study}

The 'Cost of Haemophilia in Europe: a Socioeconomic Survey' (CHESS) study was a cross-sectional, retrospective study carried out in 2015 , where patients aged $\geq 18$ years with severe haemophilia in five European countries (France, Germany, Italy, Spain and the UK) were invited to participate ${ }^{[14]} .1,285$ patients were recruited by 139 haematologists and haemophilia care providers based in hospitals and clinics. Data were collected using two questionnaire forms: the patient record form (PRF) was completed by physicians and a Patient and Public Involvement and Engagement form (PPIE) was completed by individual patients. Full details of the methodology for data collection have been published ${ }^{[14]}$.

Physicians reported the number of comorbidities diagnosed at the time of consultation, hospital admissions in the previous year, the presence of a target joint (binary variable), level of adherence to prescribed factor replacement therapy (high or low/medium, based on the physician's records) and the severity of chronic pain (according to clinical assessment). In CHESS, primary prophylaxis was defined as receiving prophylaxis since the start of treatment for haemophilia; secondary prophylaxis was defined as switching to prophylaxis from on-demand treatment ${ }^{[15]}$. We included only patients taking a prophylaxis dose of $\geq 10 \mathrm{IU} / \mathrm{kg}$, which is the minimum effective dose ${ }^{[16]}$. Patients currently receiving on-demand treatment were not included due to their infrequent use and different requirements for adherence. Patients with a history of inhibitors or currently with inhibitors were also excluded. Additionally, patients were excluded when the ratio of factor dose to body weight exceeded 1.2 (calculated as FVIII: IU per infusion/body weight x 2; FIX: IU per infusion/body weight) because this suggested the possibility of an increased risk of thrombosis or of error in completing the questionnaire. 
Joint bleeds were defined as episodes of bleeding into joints diagnosed by the physician which were recorded as major and minor bleeds. Minor bleeds were defined as those with mild pain, minimal swelling, minimal restrictions of motion and resolution within 24 hours of treatment. Major bleeds were defined as pain, effusion, limitation of motion and failure to respond to treatment within 24 hours. The presence and number of target joints was defined as joints affected by chronic synovitis diagnosed by the physician. This definition, originally proposed in $2004^{[17]}$, was adopted following discussion with an expert advisory group.

All participants in the CHESS study provided informed consent. The CHESS protocol was approved by the Research Ethics Sub Committee of the Faculty of Health and Social Care within the University of Chester. The approval stipulated that the study was to be carried out in correspondence with regional and relevant guidelines.

Health-related quality of life assessment HRQoL was assessed using the validated tool EQ-5D-3L ${ }^{[18,19]}$. This involves patient self-reporting of their health status in five dimensions: mobility, self-care, usual activities, pain and discomfort, anxiety and depression. EQ-5D-3L index values are normally confined to the range -0.594 to 1.0 , where 1.0 represents 'perfect health', zero represents 'dead', and values less than zero are health states 'worse than dead'. We were unable to utilise predictive methodologies confined to a $0-1$ range (e.g. logistic regression, beta regression) without transforming the data EQ-5D-3L values in the sample at zero. The distribution of EQ-5D-3L values was therefore shifted so that, in this analysis, EQ-5D-3L values ranges from zero to 1.594 (as zero meaning worse than dead and 1.594 perfect health). Shifting EQ-5D-3L values does not change their distribution and will facilitate the use of a more appropriated statistical method given the complex distribution. Other techniques have been proposed, such as adding a threshold in the upper level of the EQ-5D-3L scale range (Tobit models), but the values obtained from this study are very close to the threshold which would bias the results ${ }^{[20]}$.

\section{Statistical analysis}

Descriptive analysis was conducted to summarise patient characteristics. Means were used to describe continuous variables and frequency and proportions to describe categorical variables. Independent sample t-tests and chi squared for independence tests were conducted to test for between-group differences.
Multivariate analysis was carried out using generalised linear regression models. The analyses were performed using $\mathrm{R}$ software and the function $\mathrm{glm}()$. Three models were generated with a single set of candidate covariates: the first examined the effect of the covariates on quality of life, the others examined their effect on minor and major bleeds. A gamma distribution with log link function was assumed for a quality of life model whereas a Poisson with log link function was used for the major and minor bleeds regression models. For each model, a selection approach was applied to identify the best model given its complexity and goodness of fit. Candidate covariates included all potentially important determinants of the outcomes. The model selection was based on a top-down selection, which consists of having a model with all candidate covariates and removing each covariate sequentially to see the improvement of the fit. Likelihood ratio test was the test used in the model selection process.

The set of candidate covariates were:

$$
\begin{aligned}
& y=\text { age }+ \text { target joint }+ \text { subtype }+ \text { treatment } \\
& \text { strategy + number of hospital admissions + number } \\
& \text { of comorbidities + chronic pain + adherence + } \\
& \text { infusion + (infusion rate * chronic pain) }
\end{aligned}
$$

where $y$ is the dependent variable for each model. Correlation matrix was obtained between explanatory variables in order to identify any issues regarding multicollinearity of the variables.

\section{RESULTS}

\section{Patient characteristics}

Patient characteristics are summarised in Table 1. From the CHESS population ( $n=1,285)$, excluding 58 with a current inhibitor, of 1,227 patients with severe haemophilia, 338 (26\%) provided responses for major and minor bleeds and target joints and 145 (11\%) provided an EQ-5D-3L response. Most patients had haemophilia $A$. The other participants were not included in the analysis as described in the materials and methods section.

The majority of participants were young adults ( $<30$ years old) and the mean level of comorbidity was correspondingly low, though there was marked variation in the number of concomitant conditions; this was matched by variation in admission frequency. Prophylaxis was secondary in almost two thirds of patients; the number of infusions weekly ranged 
Table 1. Demographics of the study group $(n=48)$

\begin{tabular}{|c|c|c|c|}
\hline & & SUBSET $(\mathrm{N}=338)$ & CHESS DATA $(1,285)$ \\
\hline Age & $\begin{array}{l}\text { mean (SD) } \\
\text { median (range) }\end{array}$ & $\begin{array}{l}30.86(12.07) \\
27(18-67)\end{array}$ & $\begin{array}{l}35.94(14.70) \\
32(18-88)\end{array}$ \\
\hline Haemophilia type & $\begin{array}{l}\text { A } \\
B\end{array}$ & $\begin{array}{l}283(84 \%) \\
55(16 \%)\end{array}$ & $\begin{array}{l}996(77.5 \%) \\
289(22.5 \%)\end{array}$ \\
\hline Number of patients with target joint & $\begin{array}{l}\text { Yes } \\
\text { No }\end{array}$ & $\begin{array}{l}200(59.2 \%) \\
138(40.8 \%)\end{array}$ & $\begin{array}{l}768(59.8 \%) \\
517(40.2 \%)\end{array}$ \\
\hline Number of comorbidities & $\begin{array}{l}\text { mean (SD) } \\
\text { median }\end{array}$ & $\begin{array}{l}0.80(1.28) \\
0(0-12)\end{array}$ & $\begin{array}{l}0.94(1.33) \\
1(0-12)\end{array}$ \\
\hline Number of admissions & $\begin{array}{l}\text { mean (SD) } \\
\text { median }\end{array}$ & $\begin{array}{l}0.61(1.43) \\
0(0-15)\end{array}$ & $\begin{array}{l}0.76(1.46) \\
0(0-15)\end{array}$ \\
\hline Treatment strategy & $\begin{array}{l}\text { primary } \mathrm{PPX}^{\dagger} \\
\text { secondary } \mathrm{PPX}\end{array}$ & $\begin{array}{l}123(36 \%) \\
215(64 \%)\end{array}$ & $\begin{array}{l}217(16.9 \%) \\
1068(83.1 \%)\end{array}$ \\
\hline Number of prescribed infusions per year & $\begin{array}{l}\text { mean (SD) } \\
\text { median }\end{array}$ & $\begin{array}{l}134.45(42.40) \\
156(52-364)\end{array}$ & $\begin{array}{l}124.30(50.05) \\
136.71(52-364)\end{array}$ \\
\hline Weekly infusion rate ${ }^{t t}$ & $\begin{array}{l}1 \\
1.4 \\
2 \\
3 \\
3.5 \\
5 \\
6 \\
7\end{array}$ & $\begin{array}{l}30(9 \%) \\
6(2 \%) \\
97(29 \%) \\
179(53 \%) \\
19(6 \%) \\
5(1 \%) \\
1(<1 \%) \\
1(<1 \%)\end{array}$ & $\begin{array}{l}145(21 \%) \\
10(1 \%) \\
198(29 \%) \\
276(40 \%) \\
35(5 \%) \\
20(3 \%) \\
4(1 \%) \\
1(<1 \%)\end{array}$ \\
\hline Adherence & $\begin{array}{l}\text { high } \\
\text { low }\end{array}$ & $\begin{array}{l}117(35 \%) \\
221(65 \%)\end{array}$ & $\begin{array}{l}773(60.2 \%) \\
512(39.8 \%)\end{array}$ \\
\hline Chronic pain rating & $\begin{array}{l}\text { none } \\
\text { mild } \\
\text { moderate } \\
\text { high }\end{array}$ & $\begin{array}{l}121(36 \%) \\
139(41 \%) \\
71(21 \%) \\
7(2 \%)\end{array}$ & $\begin{array}{l}461(35.9 \%) \\
474(36.9 \%) \\
301(23.4 \%) \\
49(3.8 \%)\end{array}$ \\
\hline
\end{tabular}

+ PPX Prophylaxis (see Materials and Methods for definition).

tt Numbers of patients using prophylaxis and \% of total using prophylaxis

from 1-7. Physicians reported that almost two thirds had a rating of low adherence (on a Likert scale of $1-2$ vs $3-4)$ to their prophylaxis regimen. Physicians reported pain in $64 \%$ of patients. This was rated mild in most cases but considered to be moderate in one in five patients, with few having severe pain.

Compared with the CHESS population as a whole, the subset included in this analysis were slightly younger, more likely to be using primary prophylaxis, and fewer had high adherence. However, both had more people on three times weekly administration and the distribution of pain severity was similar.

\section{Infusion rate on major bleeds}

The coefficients from the generalised models were exponentiated $(\exp \{\beta\})$ to represent the proportional change in the response variable (EQ-5D-3L score, number of major and minor bleeds). The generalised model for major bleeds showed that using primary (rather than secondary) prophylaxis, number of comorbidities, infusion rate and having mild or severe chronic pain were not statistically significant variables (Table 2). Similarly, the interaction between infusion rate and pain was not significant. In the model of best fit, major bleeds were positively associated with age (i.e. higher number of bleeds were more frequent with higher age), having a target joint and hospital admissions whereas high prophylaxis adherence was associated with less events of major bleeds. Pain at every level of severity was positively associated with number of major bleeds.

\section{Infusion rate and minor bleeds}

In the case of minor bleeds, the generalised model also showed no significant association with primary prophylaxis vs secondary prophylaxis, comorbidities, mild pain, the interactions of infusion rate and pain, 
and also with age or haemophilia subtype. In the model of best fit, the presence of target joints and admissions were positively associated with minor bleeds whereas high adherence and higher infusion rate were associated with fewer minor bleed events. The association was also positive for chronic moderate and severe pain, but not mild pain, and for the interaction between infusion rate and severe pain.

\section{Health-related quality of life}

There was no significant association in the generalised model between HRQoL and age, target joints,

comorbidities, haemophilia subtype, adherence, infusion rate, or mild or moderate pain. The model of best fit showed that HRQoL was positively associated with using lifelong prophylaxis but negatively associated with number of hospital admissions. Patients with severe chronic pain reported a substantial negative impact on HRQoL; this was slightly but significantly improved by increases in the annual infusion rate.

Analysis of the impact of infusion rate on $\mathrm{HRQ}$ oL shows a trend to incremental decrease in EQ-5D-3L score with each additional infusion per week (equivalent to 52 per year) by approximately $2 \%$, increasing to $10 \%$ reduction with daily infusions.

\section{DISCUSSION}

Prophylactic clotting factor replacement reduces major or minor bleeding, with patients on primary prophylaxis reporting significantly increased $\mathrm{HRQOL}$ [211. There is a clear relationship between bleeding and hospital admission: patients with higher bleeding frequency are more likely to be admitted, with greater impact on their day-to-day life and a reduced HRQOL. The same can be said for the impact of bleeding on increasing levels of pain and HRQOL. The absence of an association between minor bleeding and the use of primary vs secondary prophylaxis appears counter-intuitive; possible explanatory factors include the relatively low age of CHESS participants, a lower perceived relative impact of minor bleeds by adults, and a small difference in effect size between primary and secondary prophylaxis.

As shown in Table 2, a high adherence rate is significantly associated with fewer major and minor bleeds, with a corresponding decreasing trend in HRQoL. However, adherence to a lifelong prophylaxis regimen is associated with a treatment burden that imposes reductions in HRQoL. This study shows that a trend toward increasing infusion frequency per week to increase protection from bleeding may have some ceiling effects and may be associated with some decreases in HRQoL scores. It is informative to consider the additional annual treatment burden arising from two to seven infusions per week: with a median infusion frequency of three per week, this would entail up to an extra 208 infusions per year (or higher for patients currently using fewer infusions per week). It is this substantial increase in the number of infusions annually that underlies the impact on HRQoL. This dilemma could be resolved with EHL factors, which have the potential to increase trough levels with no increase or even a reduction in weekly infusions ${ }^{[22]}$.

The regression analysis further shows that an increase in the annual infusion rate in patients with severe pain is associated with a significant improvement in HRQoL score. This possibly reflects higher trough levels preventing frequent re-bleeding in damaged joints, and subsequent joint deterioration and chronic pain. This was not the case for mild or moderate levels of pain, for which the reduction in HRQoL score had little effect. This may suggest that, in $\mathrm{PwH}$ with more severe pain, having higher trough levels may have a greater benefit than those with less chronic pain and could be considered as part of the balance of risk and benefit of treatment.

The current generation of PwH in the CHESS study who have received lifelong prophylaxis are ageing with mild or moderate pain rather than the severe pain associated with less intense therapy options in older regimens ${ }^{[23]}$. This study shows that, in patients with mild or moderate pain, as with those with severe chronic pain, increasing infusion rate and adherence do not have the same impact on HRQoL or bleeds.

This study suggests that having fewer weekly infusions is more than just 'a convenience'. The burden of prophylaxis has a day-to-day impact on HRQoL. Clinical management depends on raising trough factor levels to provide greater protection against bleeds and arthropathy. These findings show that increasing the treatment burden (infusion frequency) is associated with a negative impact on HRQoL; further research is needed to determine whether it is also associated with lower adherence and compromised treatment gains.

We relied on physician reporting of pain. There is evidence that physician- and patient-reported assessments and treatment of haemophilia-related pain may not correlate well, and physicians tend to underestimate pain compared with patients ${ }^{[24-26]}$. In this study, physicians reported that almost two thirds of patients had pain, which was moderate in $21 \%$ and severe in $2 \%$; there were seven patients with 
severe pain. For comparison, the HERO study found the prevalence of haemophilia-related pain was $27 \%$ $(n=230)$ when reported by patients in an online survey, whereas six reported extreme pain/discomfort ${ }^{[12,27]}$. This suggests that, although pain is an important challenge for $\mathrm{PwH}$, the prevalence of severe pain is low and it is difficult to recruit large numbers of affected patients in a population-based study. However, the regression analysis showed a statistically strong relationship between chronic severe pain and major bleeds. Further study in a larger group of patients is therefore warranted.

Adherence was assessed from physicians' records.

Self-reported assessment has been shown to correlate well with objective measures of adherence such as pharmacy records ${ }^{[28]}$, though there is also evidence that patients may overestimate their adherence ${ }^{[29]}$. Assessment by a health provider has also been shown to correlate significantly with self assessment, though slightly less well with a patient-completed questionnaire ${ }^{[30]}$.

The mean number of infusions prescribed was approximately three per week, with a range of once weekly to once daily, but the actual number of infusions received by patients could be lower due to the level of adherence to treatment. We cannot exclude the possibility that the inverse relationship between HRQoL and infusion frequency may be due to inverse causality - i.e. that worse HRQoL may be the deciding factor when considering the option of a higher infusion frequency for a person with severe pain. However, this does not alter the observation that increasing infusion frequency does not appear to benefit people with mild or moderate pain (in terms of HRQoL). It appears that patients are willing to accept chronic mild pain (which has a negative impact on $H R Q O L)$ rather than increase infusion frequency. Therefore, infusion frequency may have both a direct and indirect effect on HRQoL. This underlines the point that optimising management is a process of balancing the burden of treatment with protection against bleeds and quality of life.

\section{CONCLUSION}

This study strengthens the evidence that pain, availability of prophylaxis and bleeding rate influence HRQoL in people with severe haemophilia. It shows that the impact of severe pain on HRQoL is mitigated by increasing protection through raising trough factor levels and subsequently requiring increased weekly infusion rates. However, improvement in HRQoL in patients with mild or moderate chronic pain may be masked by the negative impact of the increased treatment burden. Further studies are needed to evaluate the implications for factor usage, cost-benefit relationship and impact on HRQoL of new treatment strategies that offer a lower infusion frequency while maintaining higher factor levels.

\section{ACKNOWLEDGMENTS}

The study reported in this paper was funded by Novo Nordisk.

GP, KK, JO, PC, XYL and SO contributed to the analysis, preparation and interpretation of the data. JP contributed to insights and interpretation of the data. The authors would like to thank Declan Noone (HCD Economics) for his contribution to the manuscript preparation and Steve Chaplin (Haemnet) for drafting the paper and incorporating authors' comments.

Informed consent has been obtained from participants in the CHESS study, on which the study reported in this paper is based.

\section{Declaration of interests}

SO is a trustee of the Haemophilia Society and currently consulting for World Federation of Haemophilia (financial support). PC and XYL are currently employed by Novo Nordisk. JP has received grants, honoraria and non-financial support from Alnylam, Biomarin, Catalyst Bio, SOBI, Shire/Takeda, Octapharma, Sanofi and Pfizer and honoraria from Apcintex, Bayer, Novo Nordisk and Roche. $K K$ is an employee of Haemnet and a trustee of the Haemophilia Society, and has received research funding and honoraria from Bayer, CSL Behring, Novo Nordisk, Pfizer, Roche, Sobi and Takeda. JO is a Trustee of Haemnet.

\section{ORCID}

Gabriel Pedra (iD) https://orcid.org/0000-0002-2023-5224 Pia Christoffersen (iD) https://orcid.org/0000-0002-9584-8922 Kate Khair (iD) https://orcid.org/0000-0003-2001-5958 Xin Ying Lee (ID https://orcid.org/0000-0002-1102-3756 Sonia O'Hara (ID) https://orcid.org/0000-0002-9119-8336 Jamie O'Hara (iD https://orcid.org/0000-0001-8262-034X John Pasi (iD https://orcid.org/0000-0003-3394-2099

\section{REFERENCES}

1. Srivastava A, Brewer AK, Mauser-Bunschoten EP, et al; Treatment Guidelines Working Group on Behalf of The World Federation of Hemophilia. Guidelines for the management of hemophilia. Haemophilia 2013; 19: e1-47. doi: 10.1111/j.13652516.2012.02909.x.

2. Ling G, Nathwani AC, Tuddenham EGD. Recent advances in developing specific therapies for haemophilia. Br J Haematol 2018; 181: 161-172. doi: 10.1111/bjh.15084. 
3. Kruse-Jarres R, Oldenburg J, Santagostino E, et al. Bleeding and safety outcomes in persons with haemophilia A without inhibitors: results from a prospective non-interventional study in a real-world setting. Haemophilia 2019; 25(2): 213-220. doi 10.1111/hae.13655

4. Kalnins W, Schelle G, Jost K, et al. Pain therapy in haemophilia in Germany. Patient survey (BESTH study). Hamostaseologie 2015; 35(2): 167-73. doi: 10.5482/HAMO-14-03-0021.

5. Forsyth AL, Witkop M, Lambing A, et al. Associations of quality of life, pain, and self-reported arthritis with age, employment, bleed rate, and utilization of hemophilia treatment center and health care provider services: results in adults with hemophilia in the HERO study. Patient Prefer Adherence 2015; 9: 154960. doi: 10.2147/PPA.S87659.

6. Berntorp E, Dolan G, Hay C, et al. European retrospective study of real-life haemophilia treatment. Haemophilia 2017; 23: 105-114. doi: 10.1111/hae.13111.

7. Collins P, Chalmers E, Chowdary P, et al. The use of enhanced half-life coagulation factor concentrates in routine clinical practice: guidance from UKHCDO. Haemophilia 2016; 22(4): 487-98. doi: 10.1111/hae.13013

8. den Uijl IE, Fischer K, Van Der Bom JG, et al. Analysis of low frequency bleeding data: the association of joint bleeds according to baseline FVIII activity levels. Haemophilia 2011; 17(1): 41-4. doi: 10.1111/j.1365-2516.2010.02383.x.

9. Furlan R, Krishnan S, Vietri J. Patient and parent preferences for characteristics of prophylactic treatment in hemophilia. Patient Prefer Adherence 2015; 9: 1687-94. doi: 10.2147/PPA.S92520.

10. Steen Carlsson K, Andersson E, Berntorp E. Preference-based valuation of treatment attributes in haemophilia A using web survey. Haemophilia 2017; 23(6): 894-903. doi: 10.1111/ hae.13322.

11. von Mackensen S, Kalnins W, Krucker J, et al. Haemophilia patients' unmet needs and their expectations of the new extended half-life factor concentrates. Haemophilia 2017; 23(4): 566-574. doi: 10.1111/hae.13221.

12. Witkop M, Guelcher C, Forsyth A, et al. Treatment outcomes, quality of life, and impact of hemophilia on young adults (aged 18-30 years) with hemophilia. Am J Hematol 2015; 90 Suppl 2: S3-10. doi: 10.1002/ajh.24220.

13. Soucie JM, Grosse SD, Siddiqi AE, et al; Hemophilia Treatment Centers Network. The effects of joint disease, inhibitors and other complications on health-related quality of life among males with severe haemophilia A in the United States. Haemophilia 2017; 23(4): e287-e293. doi: 10.1111/hae.13275.

14. O'Hara J, Hughes D, Camp C, et al. The cost of severe haemophilia in Europe: the CHESS study. Orphanet J Rare Dis 2017; 12: 106. doi: 10.1186/s13023-017-0660-y.

15. Camp C, O'Hara J, Hughes D, et al. The relationship between bleeding and EQ-5D in severe haemophilia. Poster P-T-62. WFH World Congress, 24-28 July 2016, Orlando, USA. Available from https://www.postersessiononline. eu/173580348_eu/congresos/WFH2016/aula/-PP-T_62_ WFH2016.pdf (accessed 9 July 2020).

16. Fischer K. Low-dose prophylaxis for severe haemophilia: a little goes a long way. Haemophilia 2016; 22(3): 331-3. doi: 10.1111/hae.12853

17. Mulder K, Llinás A. The target joint. Haemophilia 2004;10 Suppl 4:152-6. doi: 10.1111/j.1365-2516.2004.00976.x.
18. The EuroQol Group. EuroQol - a new facility for the measurement of health-related quality of life. Health Policy 1990; 16: 199-208. doi: 10.1016/0168-8510(90)90421-9.

19. Brooks R. EuroQol: the current state of play. Health Policy 1996; 37: 53-72. doi: 10.1016/0168-8510(96)00822-6.

20. Hauck JW, Donner A. Wald's test as applied to hypotheses in logit analysis. J Am Stat Assoc 1977; 72: 851-53. doi: 10.2307/2286473.

21. Nugent D, O'Mahony B, Dolan G; International Haemophilia Access Strategy Council. Value of prophylaxis vs on-demand treatment: application of a value framework in hemophilia. Haemophilia 2018; 24(5): 755-765. doi: 10.1111/hae.13589.

22. Chowdary P, Carcao M, Holme PA, et al. Fixed doses of N8-GP prophylaxis maintain moderate-to-mild factor VIII levels in the majority of patients with severe hemophilia A. Res Pract Thromb Haemost 2019; 3: 542-554. doi: 10.1002/rth2.12220.

23. Fischer K, van der Bom JG, Mauser-Bunschoten EP, et al. Changes in treatment strategies for severe haemophilia over the last 3 decades: effects on clotting factor consumption and arthropathy. Haemophilia 2001; 7(5): 446-52. doi: 10.1046/j.1365-2516.2001.00545.x.

24. Lambing A, Nichols CD, Munn JE, et al. Patient, caregiver, and provider perceptions of pain and pain management in adolescents and young adults with bleeding disorders. Haemophilia 2017; 23(6): 852-860. doi: 10.1111/hae.13293.

25. Witkop M, Lambing A. Knowledge and attitudes survey in bleeding disorders providers regarding pain. Haemophilia 2015; 21(6): e465-71. doi: 10.1111/hae.12749.

26. Tagliaferri A, Franchini M, Rivolta GF, et al. Pain assessment and management in haemophilia: A survey among Italian patients and specialist physicians. Haemophilia 2018; 24(5): 766-773. doi: 10.1111/hae.13600.

27. Forsyth AL, Gregory M, Nugent D, et al. Haemophilia Experiences, Results and Opportunities (HERO) Study: survey methodology and population demographics. Haemophilia 2014; 20(1): 44-51. doi: 10.1111/hae.12239.

28. Pérez-Robles T, Romero-Garrido JA, Rodriguez-Merchan EC, et al. Objective quantification of adherence to prophylaxis in haemophilia patients aged 12 to 25 years and its potential association with bleeding episodes. Thromb Res 2016; 143: 22-7. doi: 10.1016/j.thromres.2016.04.015.

29. Guedes VG, Corrente JE, Farrugia A, et al. Comparing objective and self-reported measures of adherence in haemophilia. Haemophilia 2019; 25(5): 821-830. doi: 10.1111/ hae.13811.

30. Duncan N, Kronenberger W, Roberson C, et al. VERITASPro: a new measure of adherence to prophylactic regimens in haemophilia. Haemophilia 2010; 16(2): 247-55. doi: 10.1111/j.1365-2516.2009.02129.x.

HOW TO CITE THIS ARTICLE:

Pedra G, Christoffersen P, Khair K, Lee XY, O'Hara S, O'Hara J, Pasi J. The impact of factor infusion frequency on health-related quality of life in people with haemophilia. J Haem Pract 2020; 7(1): 102-109. doi: 10.17225/jhp00158. 
Table 2. Results of the regression analysis (coefficients, $95 \%$ confidence intervals) Values $>1.0$ represent positive associations (e.g. having a target joint is strongly associated with major bleeds); values $<1.0$ represent negative associations (e.g. having haemophilia B is negatively associated with major bleeds)

\begin{tabular}{|c|c|c|c|c|c|c|}
\hline & \multicolumn{2}{|l|}{ EQ-5D-3L } & \multicolumn{2}{|c|}{ MINOR BLEEDS } & $\begin{array}{l}\text { MAJOR BLEEL } \\
\text { FULL MODEL }\end{array}$ & BEST MODEL \\
\hline (Intercept) & $\begin{array}{l}1.6536^{\star * *} \\
(1.3891 \\
1,9794)\end{array}$ & $\begin{array}{l}1.5907^{\star * *} \\
(1.4018 \\
1.808)\end{array}$ & $\begin{array}{l}2.4910 * \star \star \\
(1.5097 \\
4.0477\end{array}$ & $\begin{array}{l}2.4330 * \star \star \\
(1.5911 \\
3.6499)\end{array}$ & $\begin{array}{l}0.2292^{*} \\
(0.0524 \\
0.8669)\end{array}$ & $\begin{array}{l}0.2959 * \\
(0.1195 \\
0.7238)\end{array}$ \\
\hline Age & $\begin{array}{l}0.9981 \\
(0.9956 \\
1.0006)\end{array}$ & - & $\begin{array}{l}0.9984 \\
(0.9927 \\
1.004)\end{array}$ & - & $\begin{array}{l}1.0199 * * * \\
(1.0088 \\
1.0309)\end{array}$ & $\begin{array}{l}1.0214^{\star \star \star} \\
(1.0110 \\
1.0317)\end{array}$ \\
\hline Having a target joint & $\begin{array}{l}0.9679 \\
(0.9147 \\
1.0242)\end{array}$ & - & $\begin{array}{l}1.6486^{* * *} \\
(1.3995 \\
1.9484)\end{array}$ & $\begin{array}{l}1.6573 * \star \star \\
(1.4130 \\
1.9506)\end{array}$ & $\begin{array}{l}2.2315^{\star \star \star} \\
(1.5382 \\
2.2098)\end{array}$ & $\begin{array}{l}2.3001^{\star \star \star} \\
(1.59 .88 \\
3.3808)\end{array}$ \\
\hline $\begin{array}{l}\text { Primary prophylaxis } \\
\text { (vs secondary) }\end{array}$ & $\begin{array}{l}1.0497 * \\
(0.9979 \\
1.1039)\end{array}$ & $\begin{array}{l}1.0447 * \\
(0.9943 \\
1.0973)\end{array}$ & $\begin{array}{l}0.9601 \\
(0.8439 \\
1.0938)\end{array}$ & - & $\begin{array}{l}0.9992 \\
(0.7624 \\
1.3190)\end{array}$ & - \\
\hline $\begin{array}{l}\text { Number of concomitant } \\
\text { diseases }\end{array}$ & $\begin{array}{l}1.0051 \\
(0.9790 \\
1.0324)\end{array}$ & - & $\begin{array}{l}1.0298 \\
(0.9740 \\
1.0873)\end{array}$ & - & $\begin{array}{l}1.0356 \\
(0.9330 \\
1.1451)\end{array}$ & - \\
\hline $\begin{array}{l}\text { Number of } \\
\text { hospitalisations }\end{array}$ & $\begin{array}{l}0.9647 * \\
(0.9329 \\
0.9977)\end{array}$ & $\begin{array}{l}0.9612 * \\
(0.9306 \\
0.9932)\end{array}$ & $\begin{array}{l}1.0712^{\star \star \star} \\
(1.0357 \\
1.1064)\end{array}$ & $\begin{array}{l}1.0683^{* * *} \\
(1.0377 \\
1.0976)\end{array}$ & $\begin{array}{l}1.0588 \\
(0.9920 \\
1.1266)\end{array}$ & $\begin{array}{l}1.0541 \\
(0.9901, \\
1.1181)\end{array}$ \\
\hline High adherence & $\begin{array}{l}0.9917 \\
(0.9446 \\
1.0411)\end{array}$ & - & $\begin{array}{l}0.8554^{\star} \\
(0.7512 \\
0.9753)\end{array}$ & $\begin{array}{l}0.8463 * \\
(0.7444 \\
0.9631)\end{array}$ & $\begin{array}{l}0.6817^{\star *} \\
(0.5198 \\
0.8955)\end{array}$ & $\begin{array}{l}0.6723^{* *} \\
(0.5141 \\
0.8804)\end{array}$ \\
\hline Having haemophilia B & $\begin{array}{l}0.9996 \\
(0.9275 \\
1.0790)\end{array}$ & - & $\begin{array}{l}1.0222 \\
(0.853 \\
1.2179)\end{array}$ & - & $\begin{array}{l}0.6977 \\
(0.4408 \\
1.0620)\end{array}$ & $\begin{array}{l}0.6877 \\
(0.4345 \\
1.0435)\end{array}$ \\
\hline $\begin{array}{l}\text { Increasing infusion rate/ } \\
\text { year }\end{array}$ & $\begin{array}{l}0.9999 \\
(0.9989 \\
1.0009)\end{array}$ & $\begin{array}{l}0.9997 \\
(0.9988 \\
1.0007)\end{array}$ & $\begin{array}{l}0.9968 * \\
(0.9936 \\
1.0000)\end{array}$ & $\begin{array}{l}0.9967 * \\
(0.9936 \\
0.9999)\end{array}$ & $\begin{array}{l}0.9977 \\
((0.9885 \\
1.0073)\end{array}$ & $\begin{array}{l}0.9955^{\star} \\
(0.9921 \\
0.9989)\end{array}$ \\
\hline Mild chronic pain & $\begin{array}{l}0.9271 \\
(0.7602 \\
1.1201)\end{array}$ & $\begin{array}{l}0.8824 \\
(0.7349 \\
1.0577)\end{array}$ & $\begin{array}{l}1.0762 \\
(0.6296 \\
1.9593)\end{array}$ & $\begin{array}{l}1.0988 \\
(0.6300 \\
1.9316)\end{array}$ & $\begin{array}{l}2.6814 \\
(0.6259 \\
12.7098)\end{array}$ & $\begin{array}{l}2.1879 * * \star \\
(1.4188 \\
3.4933)\end{array}$ \\
\hline Moderate chronic pain & $\begin{array}{l}0.8994 \\
(0.6869 \\
1.1756)\end{array}$ & $\begin{array}{l}0.8344 \\
(0.6590 \\
1.0556)\end{array}$ & $\begin{array}{l}1.8156 * \star \\
(1.0213 \\
3.2642)\end{array}$ & $\begin{array}{l}1.8877^{* *} \\
(1.0723 \\
3.3572)\end{array}$ & $\begin{array}{l}4.2172^{*} \\
(0.9855 \\
20.1387)\end{array}$ & $\begin{array}{l}3.308^{* * *} \\
(2.0707 \\
5.4543)\end{array}$ \\
\hline Severe chronic pain & $\begin{array}{l}0.1826 \star \star \star \\
(0.0969 \\
0.3437)\end{array}$ & $\begin{array}{l}0.1788^{\star * \star} \\
(0.1217 \\
0.2664)\end{array}$ & $\begin{array}{l}2.5249 \\
(0.6292 \\
9.6216)\end{array}$ & $\begin{array}{l}3.6750 * \\
(1.1677 \\
10.6275)\end{array}$ & $\begin{array}{l}4.3910 \\
(0.4313 \\
45.1077)\end{array}$ & $\begin{array}{l}3.8228^{* * *} \\
(1.9093 \\
7.545)\end{array}$ \\
\hline $\begin{array}{l}\text { Infusion rate/year * mild } \\
\text { chronic pain }\end{array}$ & $\begin{array}{l}1.0000 \\
(0.9987 \\
1.0014)\end{array}$ & $\begin{array}{l}1.0002 \\
(0.9989 \\
1.0016)\end{array}$ & $\begin{array}{l}1.0023 \\
(0.9981 \\
1.0065)\end{array}$ & $\begin{array}{l}1.0024 \\
(0.9982, \\
1.0065)\end{array}$ & $\begin{array}{l}0.9983 \\
(0.9872 \\
1.0094)\end{array}$ & - \\
\hline $\begin{array}{l}\text { Infusion rate/year * } \\
\text { moderate chronic pain }\end{array}$ & $\begin{array}{l}0.9996 \\
(0.998 \\
1.0012)\end{array}$ & $\begin{array}{l}0.9999 \\
(0.9985 \\
1.0014)\end{array}$ & $\begin{array}{l}0.9968 \\
(0.9968 \\
1.0048)\end{array}$ & $\begin{array}{l}1.0007 \\
(0.9967 \\
10046)\end{array}$ & $\begin{array}{l}1.0007 \\
(0.9967 \\
10046)\end{array}$ & - \\
\hline $\begin{array}{l}\text { Infusion rate/year * } \\
\text { severe chronic pain }\end{array}$ & $\begin{array}{l}1.0045^{\star} \\
(1.0003 \\
1.0087)\end{array}$ & $\begin{array}{l}1.0045^{\star *} \\
(1.0015 \\
1.0075)\end{array}$ & $\begin{array}{l}0.9950 \\
(0.9853 \\
1.0046)\end{array}$ & $\begin{array}{l}0.9928 * \\
(0.9841 \\
1.0014)\end{array}$ & $\begin{array}{l}0.9978 \\
(0.9819 \\
1.10135)\end{array}$ & - \\
\hline
\end{tabular}

* $P<0.05, * * P<0.01, * * * P<0.001$ 